\title{
Long-term results of heart transplantation in patients older than 60 years
}

Philippe Demers, MD, MSc, FRCSC

Susan Moffatt, MD, PhD, FRCSC

Philip E. Oyer, MD, PhD

Sharon A. Hunt, MD

Bruce A. Reitz, MD

Robert C. Robbins, MD
From the Department of Cardiothoracic Surgery, Stanford University School of Medicine, Stanford, Calif.

Received for publication Sept 14, 2002; revisions requested Oct 22, 2002; revisions received Oct 23, 2002; accepted for publication Nov 1, 2002.

Address for reprints: Robert C. Robbins, MD, Department of Cardiothoracic Surgery, Falk Cardiovascular Research Center, Stanford University School of Medicine, 300 Pasteur Dr, Stanford, CA 94305-5247 (E-mail: robbins@stanford.edu).

J Thorac Cardiovasc Surg 2003;126:224-31

Copyright $\odot 2003$ by The American Association for Thoracic Surgery

$0022-5223 / 2003 \$ 30.00+0$

doi:10.1016/S0022-5223(03)00055-2
Background: Advanced age has been traditionally considered a relative contraindication for heart transplantation. Older patients are now considered as potential candidates for heart transplantation. The objective of this study was to evaluate the long-term results of heart transplantation in patients older than 60 years.

Methods: Between 1986 and 2001, 81 patients aged between 60 and 70 years (mean, $63 \pm 2$ years) underwent heart transplantation. These patients were compared with 403 adult recipients younger than 60 years (mean, $47 \pm 11$ years) who underwent transplantation during the same period.

Results: Thirty-day mortality was 6\% (5/81) and 6\% (25/403) in the older and younger patients, respectively $(P=\mathrm{NS})$. Actuarial survival at 1,5 , and 10 years was $88 \% \pm 4 \%$ versus $83 \% \pm 2 \%, 75 \% \pm 5 \%$ versus $69 \% \pm 2 \%$, and $50 \% \pm 9 \%$ versus $51 \% \pm 3 \%$ in the older and younger patients, respectively $(P=\mathrm{NS})$. Older patients had significantly fewer rejection episodes $(P=.003)$. Freedom from allograft coronary artery disease at 1,5 , and 10 years was $98 \% \pm 2 \%$ versus $92 \% \pm 2 \%, 85 \%$ $\pm 6 \%$ versus $76 \% \pm 3 \%$, and $81 \% \pm 7 \%$ versus $68 \% \pm 3 \%(P=.1)$. The incidences of infectious complication, cytomegalovirus infection, and posttransplant lymphoproliferative disorder were similar between the 2 groups, but older recipients were more likely to have a nonposttransplant lymphoproliferative disorder cancer $(P$ $=.002$ ). Age at transplantation was not identified as an independent risk factor for early and late death.

Conclusion: Heart transplantation in selected patients aged 60 years and older results in survival comparable with that of younger patients. Older patients have a lower risk of rejection but an increased risk of development of a nonposttransplant lymphoproliferative disorder cancer. Advanced age per se should not be considered as an exclusion criterion for transplantation.

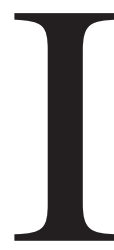

nitially, heart transplantation was restricted to patients younger than 50 years of age. ${ }^{1}$ After 1981, when cyclosporine (INN: ciclosporin) was introduced, survival after heart transplantation progressively improved, and recipient selection criteria became less restrictive. These evolving selection criteria included a progressive extension of the upper age limit for potential candidates, initially up to 60 years and ultimately up to and above 70 years. Support for criteria relaxation came mostly from small single-center studies describing equivalent short-term survival, as well as lower rejection rates, in older recipients. $^{2-5}$ However, other authors have reported reduced survival after transplantation in patients older than 60 years. ${ }^{6}$ Moreover, the Registry of the International Society for Heart and Lung Transplantation (ISHLT) is still reporting increasing recipient age as a strong risk factor that adversely affects 1- and 5-year 
TABLE 1. Preoperative characteristics of 484 consecutive adult patients undergoing first heart transplantation subdivided according to age at transplantation

\begin{tabular}{|c|c|c|c|c|c|c|}
\hline & \multicolumn{2}{|c|}{ All patients $(n=484)$} & \multicolumn{2}{|c|}{$18-60$ y $(n=403)$} & \multicolumn{2}{|c|}{$\geq 60$ y $(n=81)$} \\
\hline & $\mathbf{N}$ & $\%$ & $\mathbf{N}$ & $\%$ & $\mathbf{N}$ & $\%$ \\
\hline $\begin{array}{l}\text { Age (y) } \\
\text { Range }\end{array}$ & \multicolumn{2}{|c|}{$\begin{array}{c}50 \pm 12 \\
18-70\end{array}$} & \multicolumn{2}{|c|}{$\begin{array}{c}47 \pm 11 \dagger \\
18-59\end{array}$} & \multicolumn{2}{|c|}{$\begin{array}{c}63 \pm 2 \dagger \\
60-70\end{array}$} \\
\hline \multicolumn{7}{|l|}{ Sex } \\
\hline Male & 398 & 82 & 326 & 81 & 72 & 89 \\
\hline Female & 86 & 18 & 77 & 19 & 9 & 11 \\
\hline \multicolumn{7}{|l|}{ Race } \\
\hline White & 379 & 78 & 312 & 77 & 67 & 83 \\
\hline Other & 105 & 22 & 91 & 23 & 14 & 17 \\
\hline BMI & \multicolumn{2}{|c|}{$25 \pm 4$} & \multicolumn{2}{|c|}{$25 \pm 4$} & \multicolumn{2}{|c|}{$25 \pm 4$} \\
\hline $\mathrm{BMI} \leq 19$ & 26 & 5 & 24 & 6 & 2 & 3 \\
\hline $\mathrm{BMI} \geq 31$ & 44 & 9 & 36 & 9 & 8 & 10 \\
\hline \multicolumn{7}{|l|}{ Cardiomyopathy } \\
\hline Ischemic & 184 & 38 & 142 & 35 & 42 & 52 \\
\hline Idiopathic & 225 & 47 & 195 & 48 & 30 & 37 \\
\hline Other & 75 & 15 & 66 & 17 & 9 & 11 \\
\hline \multicolumn{7}{|c|}{ Transplant status (UNOS) } \\
\hline 1 & 167 & 36 & 140 & 36 & 27 & 34 \\
\hline 2 & 317 & 64 & 263 & 64 & 74 & 66 \\
\hline \multicolumn{7}{|l|}{ Preoperative support } \\
\hline Inotropes & 121 & 26 & 97 & 25 & 24 & 30 \\
\hline LVAD & 40 & 9 & 38 & 10 & 2 & 3 \\
\hline ABPP & 6 & 1 & 5 & 1 & 1 & 1 \\
\hline Previous sternotomy & 204 & 42 & 155 & $39 \dagger$ & 49 & $61 \dagger$ \\
\hline PRA $\geq 10$ & 26 & 5 & 24 & 6 & 2 & 3 \\
\hline CMV positive & 291 & 60 & 234 & 58 & 57 & 70 \\
\hline Waiting time (d) & \multicolumn{2}{|c|}{$168 \pm 203$} & \multicolumn{2}{|c|}{$156 \pm 195 \dagger$} & \multicolumn{2}{|c|}{$219 \pm 229 \dagger$} \\
\hline
\end{tabular}

BMI, Body mass index; UNOS, United Network for Organ Sharing; LVAD, left ventricular assist device; IABP, intra-aortic balloon pump; PRA, panel reactive antibodies; $C M V$, cytomegalovirus.

${ }^{*} P<.05, \uparrow P<.01$ by either $\left(\chi^{2}\right)$ or $t$ test.

survival after heart transplantation. ${ }^{7}$ At Stanford University, the heart transplantation program was initiated in $1968^{8,9}$ and heart transplantation was offered to selected patients aged 60 years and older starting in 1986 if these patients were otherwise acceptable candidates for transplantation. Today, considering the limited availability of donor organs and the advent of new concepts, such as left ventricular assist device technology as a definitive therapy for endstage congestive heart failure ${ }^{10}$ and alternate recipient lists for heart transplantation, ${ }^{11}$ determination of the optimal therapeutic option in patients older than 60 years presenting with end-stage heart failure is more challenging than ever. The objective of this study was to evaluate the long-term results of cardiac transplantation in patients aged 60 years and older to facilitate the determination of appropriate recipient selection guidelines.

\section{Patients and Methods}

\section{Patients}

Between October 1986 and July 2001, 484 consecutive adult patients ( $\geq 18$ years) underwent primary orthotopic heart transplantation at Stanford University Medical Center. Patients were divided into groups according to the recipient's age at the time of transplantation: 81 (17\% of total) patients were aged 60 years and older (mean age, $63 \pm 2$ years; range, 60-70 years; 15 patients were older than 65 years), and 403 patients were aged between 18 and 59 years (mean age, $47 \pm 11$ years). Pretransplantation evaluation of the recipients was the same in all patients: we used the same eligibility criteria in older and younger patients. In patients older than 50 years, evaluation involved an assessment of clinical conditions commonly seen with advancing age, such as malignancies, carotid and peripheral vascular disease, and end-organ dysfunction caused by diabetes mellitus. Although difficult to evaluate quantitatively with the available data, a selection bias was clearly present in the evaluation of older candidates to avoid selecting borderline recipients with several risk factors in addition to advanced age.

The preoperative characteristics of the 2 groups are listed in Table 1. Older patients were more likely to have ischemic cardiomyopathy as the indication for transplantation (52\% vs $35 \%$ ), but this difference did not reach statistical significance. The patients older than 60 years had a higher prevalence of previous sternotomy (61\% vs $39 \%, P=.01$ ), and their mean waiting time before transplantation was significantly longer (219 vs 156 days, $P=$ .01). However, there was no significant difference in the other 
TABLE 2. Donor characteristics of 484 consecutive adult patients undergoing first heart transplantation subdivided according to age at transplantation

\begin{tabular}{|c|c|c|c|c|c|c|}
\hline & \multicolumn{2}{|c|}{ All patients $(n=484)$} & \multicolumn{2}{|c|}{$18-60$ y $(n=403)$} & \multicolumn{2}{|c|}{$\geq 60$ y $(n=81)$} \\
\hline & $\mathbf{N}$ & $\%$ & $\mathbf{N}$ & $\%$ & $\mathbf{N}$ & $\%$ \\
\hline Age (y) & \multicolumn{2}{|c|}{$30 \pm 11$} & \multicolumn{2}{|c|}{$30 \pm 11$} & \multicolumn{2}{|c|}{$30 \pm 11$} \\
\hline $\begin{array}{l}\text { Donor age } \geq 50 \text { y } \\
\text { Sex }\end{array}$ & 25 & 5 & 18 & 5 & 7 & 9 \\
\hline Male & 364 & 75 & 301 & 75 & 63 & 78 \\
\hline Female & 120 & 25 & 102 & 25 & 18 & 22 \\
\hline Sex mismatch & 71 & 15 & 59 & 15 & 12 & 15 \\
\hline \multicolumn{7}{|l|}{ Race } \\
\hline White & 357 & 73 & 306 & 76 & 51 & 63 \\
\hline Other & 127 & 27 & 97 & $24 \dagger$ & 30 & $37 \dagger$ \\
\hline Race mismatch & 183 & 38 & 150 & 37 & 33 & 41 \\
\hline Weight (kg) & \multicolumn{2}{|c|}{$77 \pm 15$} & \multicolumn{2}{|c|}{$77 \pm 16$} & \multicolumn{2}{|c|}{$78 \pm 13$} \\
\hline $\mathrm{D} / \mathrm{R}$ weight ratio $<0.80$ & 29 & 6 & 24 & 6 & 5 & 6 \\
\hline \multicolumn{7}{|l|}{ Cause of death } \\
\hline Trauma & 346 & 71 & 292 & 72 & 54 & 67 \\
\hline CVA & 96 & 20 & 75 & 19 & 21 & 26 \\
\hline Other & 42 & 9 & 36 & 9 & 6 & 7 \\
\hline CMV mismatch & 101 & 22 & 86 & 23 & 15 & 19 \\
\hline
\end{tabular}

$D / R$, Donor/recipient; $C V A$, cerebrovascular accident; $C M V$, cytomegalovirus.

${ }^{*} P<.05,+P<.01$ by either $\left(\chi^{2}\right)$ or $t$ test.

preoperative variables, including United Network for Organ Sharing (UNOS) status at the time of transplantation and preoperative use of inotropes or mechanical support.

Donor selection criteria were the same for all patients, and allocation was made according to UNOS status and waiting time. No effort was made to match older or so-called marginal donor hearts with older recipients. Donor characteristics for the 2 groups are listed in Table 2. Donors older than 50 years were used for $5 \%$ of the younger patients and $9 \%$ of the older patients $(P=\mathrm{NS})$. Patients 60 years and older were more likely to get an organ from a nonwhite donor $(37 \%$ vs $24 \%, P=.01$ ). However, the proportion of female donors, sex mismatch (female donor to male recipient), race mismatch, and weight mismatch (donor/recipient weight ratio $<0.80$ ) were not statistically different between the 2 groups.

\section{Surgical Technique}

All donor hearts were harvested with cold hyperkalemic crystalloid Stanford solution, and cold storage was used during transportation. The donor cardiectomy and the technique of orthotopic cardiac replacement have not changed significantly since its initial description by Lower and Shumway. ${ }^{12}$ However, a bicaval implantation technique has been used since 1996 in all patients. There was no significant difference in mean allograft ischemic time and cardiopulmonary bypass time between the 2 groups (Table 3 ).

\section{Immunosuppressive Protocol}

Immunosuppression consisted of induction therapy with RATG or OKT3 (introduced in July 1987) and maintenance immunosuppression with cyclosporine, azathioprine, or mycophenolate mofetil (introduced in January 1997) and steroids. ${ }^{9}$ Immunosuppressive protocols were the same for the younger and older patients.

\section{Definitions and Follow-up}

Acute rejection was diagnosed on the basis of histologic studies of the endomyocardial biopsy specimens. Rejection severity was graded according to the ISHLT rejection grading system. ${ }^{13}$ Infection was defined as any infection requiring intravenous antibiotics. Allograft coronary artery disease was diagnosed on the basis of coronary angiography and more recently with intravascular coronary ultrasonography or at autopsy. Any lesion causing 50\% or greater stenosis in at least one major coronary artery was considered significant. Early death was defined as any death occurring within the first 90 days after transplantation.

Patients and their primary care physicians were contacted periodically, and clinical data were entered prospectively in the Stanford Transplant Database. Follow-up was $100 \%$ complete and averaged $68 \pm 53$ months for the entire series (maximal follow-up, 15.9 years; 244 patients still at risk at 5 years and 103 patients at risk at 10 years).

\section{Statistical Analysis}

Continuous variables are reported as means $\pm \mathrm{SD}$, and categoric variables are reported as proportions and percentages. Comparisons between continuous variables were made by using the unpaired 2-tailed $t$ test. Categoric variables were compared by using the $\chi^{2}$ test. The actuarial life-table method was used to generate survival estimates, which are reported with $95 \%$ confidence limits. A log-rank test was used to compare survival estimates between groups. A multivariable forward stepwise Cox proportional hazards model was used after exploratory analysis of 28 recipient and donor variables (Appendix 1) to identify independent risk factors for early and late deaths. The $P$ value for inclusion and retention of variables in the models were .10 and .08 , respectively. All 
TABLE 3. Intraoperative and postoperative data of 484 consecutive adult patients undergoing first heart transplantation subdivided according to age at transplantation

\begin{tabular}{|c|c|c|c|c|c|c|c|}
\hline & \multicolumn{2}{|c|}{ All patients $(n=484)$} & \multicolumn{2}{|c|}{$18-60$ y $(n=403)$} & \multicolumn{3}{|c|}{$\geq 60$ y $(n=81)$} \\
\hline & $\mathbf{N}$ & $\%$ & $\mathbf{N}$ & $\%$ & $\mathbf{N}$ & & $\%$ \\
\hline $\begin{array}{l}\text { Ischemic time (min) } \\
\text { Ischemia } \geq 240 \mathrm{~min}\end{array}$ & 41 & 9 & 33 & 9 & 8 & $183 \pm 42$ & 10 \\
\hline CPB time (min) & & & & & & $128 \pm 31$ & \\
\hline 30-Day mortality & 30 & 6 & 25 & 6 & 5 & & 6 \\
\hline $\begin{array}{l}\text { Hospital stay (d) } \\
\text { Follow-up (mo) }\end{array}$ & & & & & & $\begin{array}{l}20 \pm 21 \\
59+42\end{array}$ & \\
\hline
\end{tabular}

$C P B$, Cardiopulmonary bypass.

${ }^{*} P<.05, \dagger P<.01$ by either $\chi^{2}$ or $t$ test.

statistical analyses were performed with the SPSS program (version 10.0; SPSS Inc, Chicago, Ill).

\section{Results}

Perioperative Results

Thirty-day mortality was $6 \%(5 / 81)$ in the patients aged 60 years and older and 6\% (25/403) in the younger patients $(P$ $=$ NS, Table 3). Mean hospital stay was similar in both groups (Table 3).

\section{Survival}

Actuarial survival estimates at 1,5 , and 10 years for all patients were $84 \% \pm 2 \%, 70 \% \pm 2 \%$, and $51 \% \pm 3 \%$, respectively (Figure 1). Actuarial survival at 1,5 , and 10 years was not statistically different between patients older than 60 years and patients younger than 60 years $(88 \% \pm$ $4 \%$ vs $83 \% \pm 2 \%, 75 \% \pm 5 \%$ vs $73 \% \pm 2 \%$, and $50 \% \pm$ $9 \%$ vs $51 \% \pm 3 \%$, respectively; Figure 2). Causes of death in the older and younger recipients are listed in Table 4.

\section{Multivariable Analysis for Early and Late Deaths}

As shown in Table 5, the only significant independent determinants of early death ( $<90$ days) were female donor, previous sternotomy, and preoperative support with inotropes. Multivariable analysis identified earlier era (19861992), sex mismatch, racial mismatch, and ischemic cardiomyopathy as independent risk factors for late death $(\geq 90$ days, Table 6). Increasing recipient age was not identified as an independent risk factor for early and late death.

\section{Acute Rejection}

Patients aged 60 years and older had $2.0 \pm 1.1$ acute allograft rejection episodes per patient compared with $2.6 \pm$ 1.8 episodes per patient in younger recipients, a difference that was statistically significant $(P=.003$, Table 7$)$. Moreover, actuarial freedom from acute rejection at 3 months, 1 year, and 2 years was significantly higher in older patients $(49 \% \pm 6 \%$ vs $33 \% \pm 2 \%, 39 \% \pm 6 \%$ vs $27 \% \pm 2 \%$, and $36 \% \pm 6 \%$ vs $24 \% \pm 2 \% ; P=.01)$.

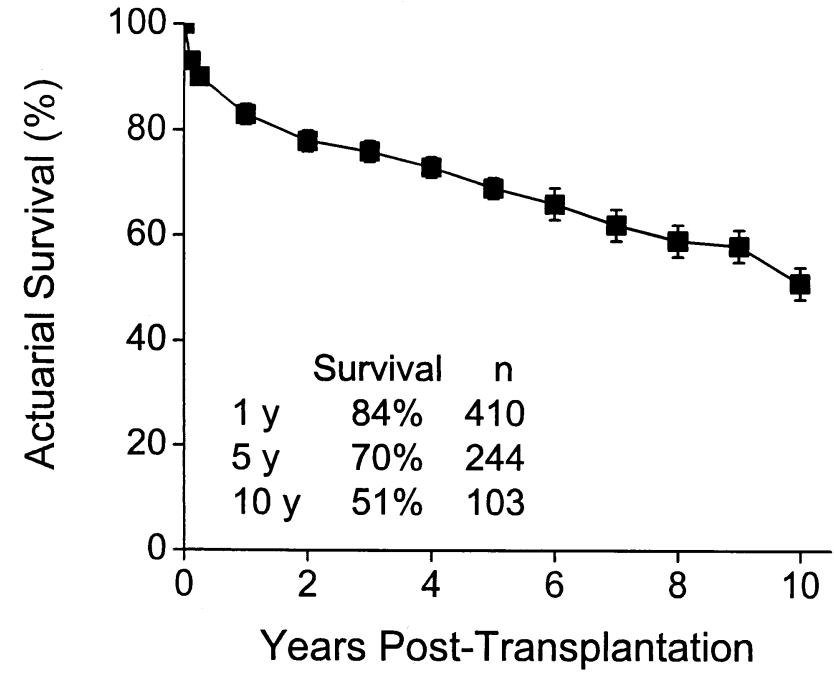

Figure 1. Actuarial estimates of survival after heart transplantation in all patients.

\section{Infection}

Actuarial freedom from any infection at 3 months and 1, 5, and 10 years after transplantation was not significantly different between older and younger patients. Moreover, freedom from cytomegalovirus infection at 3 months and 1 , 5 , and 10 years was also similar in both groups (Table 7).

\section{Allograft Coronary Artery Disease}

Actuarial freedom from allograft coronary artery disease at 1,5 , and 10 years was $98 \% \pm 2 \%$ versus $92 \% \pm 2 \%, 85 \%$ $\pm 6 \%$ versus $76 \% \pm 3 \%$, and $81 \% \pm 7 \%$ versus $68 \% \pm 3 \%$ in older and younger patients, respectively, a difference that failed to reach statistical significance $(P=.1$, Figure 3$)$.

\section{Posttransplant Lymphoproliferative Disorder and Nonposttransplant Lymphoproliferative Disorder Cancer}

Actuarial freedom from posttransplant lymphoproliferative disorder (PTLD) 1, 5, and 10 years after transplantation was 


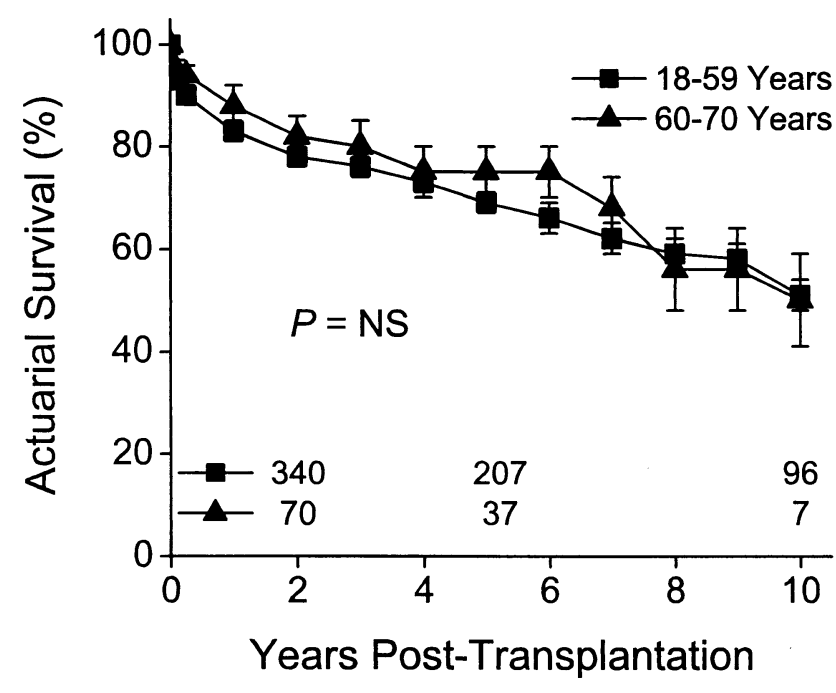

Figure 2. Actuarial estimates of survival after heart transplantation according to age at transplantation.

TABLE 4. Causes of death in 484 consecutive adult patients undergoing first heart transplantation subdivided according to age at transplantation

\begin{tabular}{|c|c|c|c|c|}
\hline & \multicolumn{2}{|c|}{$\begin{array}{c}18-60 y \\
(n=403)\end{array}$} & \multicolumn{2}{|c|}{$\begin{array}{c}\geq 60 y \\
(n=81)\end{array}$} \\
\hline & $\mathbf{N}$ & $\%$ & $\mathbf{N}$ & $\%$ \\
\hline Acute graft failure & 9 & 5 & 1 & 4 \\
\hline Acute rejection & 17 & 10 & 3 & 13 \\
\hline Infection & 45 & 27 & 5 & 21 \\
\hline Allograft coronary artery disease & 27 & 16 & 3 & 13 \\
\hline Malignancy & 24 & 14 & 3 & 13 \\
\hline Cerebrovascular accident & 2 & 1 & 4 & 16 \\
\hline Other & 40 & 24 & 6 & 25 \\
\hline
\end{tabular}

TABLE 5. Independent risk factors for early mortality ( $\leq 90$ days) after heart transplantation according to Cox proportional-hazards model

\begin{tabular}{lcclc}
\hline Variable & $\boldsymbol{\beta}$ & Hazard ratio & 95\% CL & $\boldsymbol{P}$ value \\
\hline Female donor & 2.05 & 7.7 & $3.1-19.1$ & .001 \\
$\begin{array}{l}\text { Previous sternotomy } \\
\text { Preoperative support }\end{array}$ & 0.84 & 2.3 & $1.0-5.4$ & .05 \\
$\quad$ Inotropic drugs & 0.99 & 2.7 & $1.2-6.3$ & .02 \\
\hline
\end{tabular}

$C L$, Confidence limit.

$97 \% \pm 2 \%$ versus $99 \% \pm 1 \%, 97 \% \pm 2 \%$ versus $97 \% \pm$ $1 \%$, and $97 \% \pm 2 \%$ versus $93 \% \pm 2 \%$ in older and younger recipients, respectively ( $P=$ NS, Table 7). Actuarial freedom from non-PTLD cancer at 1, 5, and 10 years was $92 \%$ $\pm 3 \%$ versus $99 \% \pm 1 \%, 76 \% \pm 6 \%$ versus $89 \% \pm 2 \%$, and $68 \% \pm 9 \%$ versus $80 \% \pm 3 \%$ in the older and younger
TABLE 6. Independent risk factors for late mortality (>90 days) after heart transplantation according to Cox proportional-hazards model

\begin{tabular}{lcccc}
\hline Variable & $\boldsymbol{\beta}$ & Hazard ratio & $\mathbf{9 5 \%} \mathbf{C L}$ & $\boldsymbol{P}$ value \\
\hline Era 1986-1992 & 0.53 & 1.7 & $1.1-2.7$ & .02 \\
Sex mismatch & 0.64 & 1.9 & $1.1-3.2$ & .02 \\
Race mismatch & 0.38 & 1.5 & $1.0-2.2$ & .07 \\
Ischemic cardiomyopathy & 0.42 & 1.5 & $1.0-2.3$ & .05 \\
\hline
\end{tabular}

TABLE 7. Postoperative morbidity of 484 consecutive adult patients undergoing first heart transplantation subdivided according to age at transplantation

\begin{tabular}{|c|c|c|c|}
\hline & $\begin{array}{c}18-60 y \\
(n=403)\end{array}$ & $\begin{array}{c}\geq 60 y \\
(n=81)\end{array}$ & $P$ value \\
\hline No. of rejection episodes & $2.6 \pm 1.8$ & $2.0 \pm 1.1$ & .003 \\
\hline Freedom from acute rejection $(\%)$ & & & .01 \\
\hline $3 \mathrm{mo}$ & $33 \pm 2$ & $49 \pm 6$ & \\
\hline $1 \mathrm{y}$ & $27 \pm 2$ & $39 \pm 6$ & \\
\hline $5 y$ & $23 \pm 2$ & $34 \pm 6$ & \\
\hline $10 y$ & $20 \pm 3$ & $34 \pm 6$ & \\
\hline Freedom from any infection (\%) & & & NS \\
\hline $3 \mathrm{mo}$ & $58 \pm 3$ & $60 \pm 6$ & \\
\hline $1 \mathrm{y}$ & $38 \pm 3$ & $39 \pm 6$ & \\
\hline 5 y & $25 \pm 3$ & $33 \pm 6$ & \\
\hline 10 y & $24 \pm 3$ & $30 \pm 6$ & \\
\hline Freedom from CMV infection (\%) & & & NS \\
\hline $3 \mathrm{mo}$ & $83 \pm 2$ & $88 \pm 4$ & \\
\hline $1 \mathrm{y}$ & $72 \pm 3$ & $75 \pm 5$ & \\
\hline 5 y & $69 \pm 3$ & $70 \pm 6$ & \\
\hline 10 y & $67 \pm 3$ & $70 \pm 6$ & \\
\hline Freedom from PTLD (\%) & & & NS \\
\hline 1 y & $99 \pm 1$ & $97 \pm 2$ & \\
\hline $5 y$ & $97 \pm 1$ & $97 \pm 2$ & \\
\hline $10 y$ & $93 \pm 2$ & $97 \pm 2$ & \\
\hline Freedom from non-PTLD cancer $(\%)$ & & & .002 \\
\hline 1 y & $99 \pm 1$ & $92 \pm 3$ & \\
\hline 5 y & $89 \pm 2$ & $76 \pm 6$ & \\
\hline $10 \mathrm{y}$ & $80 \pm 3$ & $68 \pm 9$ & \\
\hline
\end{tabular}

$N S$, Not significant; $C M V$, cytomegalovirus.

patients, respectively, a difference that was statistically significant $(P=.002$, Figure 4$)$.

\section{Discussion}

Heart transplantation is the best treatment option for selected patients with end-stage heart failure who have failed medical therapy and are not amenable to other treatment options. Because of the critical shortage of donor organs, selection of candidates for transplantation is based on the potential for maximal benefit in terms of functional recovery and long-term survival. The upper age limit used to select potential candidates for heart transplantation has significantly changed over the last 20 years, and it is still a matter of debate. ${ }^{14,15}$ According to the 2000 Report from 
the Registry of the International Society for Heart and Lung Transplantation, increasing recipient age remains an independent risk factor that adversely affects 1 - and 5-year survival after heart transplantation, with a progressive increase in risk when recipient age is greater than 55 years. $^{7}$ Despite this, several centers no longer consider advanced age as an absolute contraindication for heart transplantation and are now accepting selected patients older than 60 years when they are otherwise appropriate candidates for transplantation. Appropriate evaluation and selection of these elderly patients is obviously critical ${ }^{16}$ because several clinical conditions, such as malignancies, are more commonly seen in this age group, ${ }^{17}$ which might jeopardize survival after transplantation. However, despite this change in eligibility criteria over the years, few studies have evaluated the long-term results of heart transplantation in older patients.

Initially, heart transplantation was restricted to patients younger than 50 years. ${ }^{1,7}$ Later, as short- and long-term survival after transplantation improved, selection criteria, including age, were progressively liberalized in most heart transplantation programs. Evidence for such change in upper age limit came from several studies reporting that morbidity and mortality after heart transplantation were not significantly increased in selected older patients. ${ }^{2-5}$ These initial reports, however, were limited by small numbers of patients and short-term follow-up. However, other authors have subsequently reported that survival after heart transplantation in patients older than 60 years was significantly reduced, with an increase in the incidence of life-threatening infectious complications and malignancies. ${ }^{6}$ Interestingly, most of these early studies suggested that patients older than 60 years had fewer acute rejection episodes after transplantation, ${ }^{2-6}$ and it was postulated that older recipients, having decreased immune reactivity and reduced T-cell function, might require less immunosuppression. Decreased immune reactivity and increased susceptibility of the elderly patients to the effects of immunosuppressive regimens have also been proposed to explain the higher incidence of infectious complications and malignancies after transplantation. ${ }^{6}$ More recently, Borkon and colleagues ${ }^{18}$ reported that age greater than 55 years at the time of transplantation was an independent risk factor for late death in their contemporary series of 153 heart transplant recipients, with an estimated 5-year survival of $56 \%$ in these patients compared with $78 \%$ in patients younger than 55 years. These authors also observed a greater incidence of life-threatening infections in older recipients, with the same incidence of acute rejection in younger and older patients. These results were not confirmed by other recent reports. ${ }^{19,20}$ Baron and coworkers ${ }^{19}$ reported their results in a series of 70 patients aged between 60 and 65 years transplanted over a period of 11 years and noted similar survival in these patients and in patients younger than 60 years transplanted during the same period,

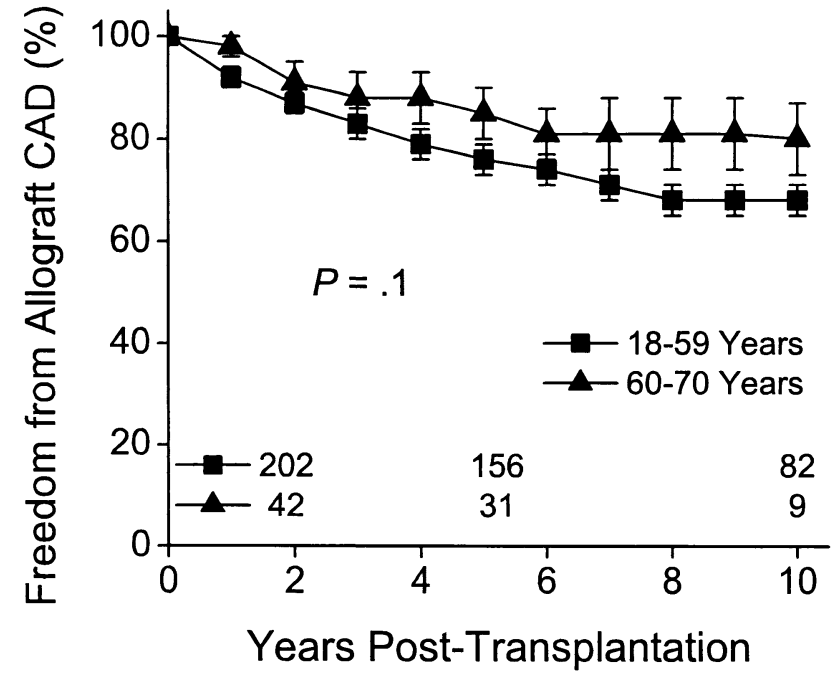

Figure 3. Freedom from allograft coronary artery disease (CAD) after heart transplantation according to age at transplantation.

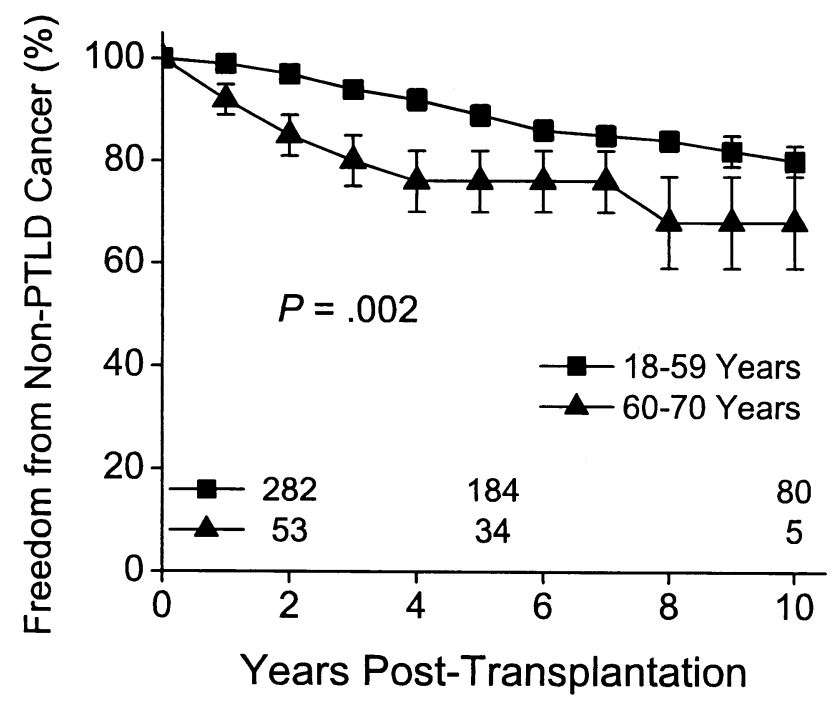

Figure 4. Freedom from non-PTLD cancer after heart transplantation according to age at transplantation.

without any difference between these 2 groups in the incidence of infection and malignancy after transplantation.

At Stanford University, heart transplantation was offered to selected patients aged 60 years and older starting in 1986 if these patients were otherwise acceptable candidates for transplantation by using the same selection criteria as in younger candidates. These recipients were listed on the regular UNOS waiting list, and allocation of donor organs was made according to UNOS status and waiting time. No effort was made to match older or so-called marginal donor hearts with older recipients. Immunosuppression protocol, 
infection prophylaxis, postoperative management, and monitoring of rejection were the same in the older patients. Older and younger patients were well matched for almost all pretransplant recipient characteristics and donor characteristics, except previous operation, which was more frequent in the former, and waiting time, which was longer in the older recipients. Despite these differences in baseline characteristics, we found that perioperative mortality and hospital length of stay were comparable in both groups. Multivariable analysis revealed that age at transplantation was not an independent predictor of early death. Previous sternotomy, use of a female donor, and inotropic support at the time of transplantation were the only independent risk factors for early death identified. Moreover, we observed that long-term survival after transplantation was similar in the 2 groups. Similarly, age at transplantation was not identified in the multivariable analysis as an independent risk factor for late death. These results are consistent with those of previously discussed series. ${ }^{3-5,19,20}$

As reported by several authors, ${ }^{3-6}$ the incidence of acute rejection was lower in the older patients. In our series, although not statistically significant, the incidence of allograft coronary artery disease was lower in the patients older than 60 years. Contrary to the results of some previous reports, ${ }^{5,6,18}$ we did not find any difference in the incidence of infectious complications and cytomegalovirus infection in the 2 groups. However, even if the incidence of PTLD was similar in the younger and older patients, the incidence of non-PTLD cancer was significantly higher in the patients aged 60 years and older. Despite this finding, the proportion of death caused by cancer was comparable in the 2 groups. Increasing age is a known risk factor for posttransplant malignancies, ${ }^{17}$ and the importance of a thorough screening program in the pretransplant evaluation of older candidates and those with preexisting malignancies has already been demonstrated. ${ }^{16}$ Taken together, these findings suggest that patients older than 60 years might benefit from more stringently tailored immunosuppression regimens.

Long-term survival in this series compares favorably with the recently published midterm results of patients listed on an alternate recipient list at UCLA and transplanted with marginal organs. ${ }^{11}$ In the recent report from the REMATCH investigators, survival of patients supported with a left ventricular assist device as a definitive therapy for end-stage heart failure was $52 \%$ at 1 year and $23 \%$ after 2 years ${ }^{11}$ compared with $88 \%$ and $82 \%$, respectively, in the patients older than 60 years in this series. Age greater than 65 years was the most common reason for ineligibility for transplantation and for enrollment in the REMATCH trial. On the basis of these data, if transplantation had been offered to the patients enrolled in REMATCH because of advanced age only and who were allocated to the left ventricular assist device arm, survival might have been improved.
A limitation of this study is the evolving nature of the selection process of older potential candidates over 15 years. The eligibility criteria used were the same for all patients, but a subjective selection bias was certainly present in the evaluation of older patients to avoid selecting borderline recipients with several risk factors in addition to advanced age. Quantification of this bias was difficult because of incomplete data regarding the recipient acceptance ratio over the 15-year period of this study. Also, the small number of patients, especially those older than 65 years, compared with numbers in large registry databases, such as the ISHLT registry, ${ }^{7}$ limits the inferences made from these results and increases the risk of a type II statistical error.

In summary, our experience with selected patients aged 60 years and older is favorable and indicates that heart transplantation can be successfully performed in these patients, with long-term survival comparable with that seen in younger patients. Age between 60 and 70 years per se should not be considered an absolute contraindication to heart transplantation, even in patients who have undergone previous cardiac operation. Care must be taken in the pretransplant evaluation of patients older than 60 years to identify concomitant medical condition that might limit survival after transplantation. Finally, more strictly tailored immunosuppression, with or without induction therapy, might be beneficial in these patients to reduce the incidence of non-PTLD malignancies.

We thank our surgical and medical colleagues, fellows, and residents for their significant contributions to the Stanford University Heart Transplantation Program. They have all cared for a large number of the patients described in the present report.

\section{References}

1. Copeland JG, Stinson EB. Human heart transplantation. Curr Probl Cardiol. 1979;4:1-51

2. Carrier M, Emery RW, Riley JE, Levinson MM, Copeland JG. Cardiac transplantation in patients over 50 years of age. J Am Coll Cardiol. 1986;8:285-8.

3. Frazier OH, Macris MP, Duncan JM, Van Buren CT, Cooley DA. Cardiac transplantation in patients over 60 years of age. Ann Thorac Surg. 1988;45:129-32.

4. Fabbri A, Sharples LD, Mullins P, Caine N, Large S, Wallwork J. Heart transplantation in patients over 54 years of age with triple-drug therapy immunosuppression. J Heart Lung Transplant. 1992;11:92932.

5. Heroux AL, Costanzo-Nordin MR, O'Sullivan JE, Kao WG, Liao Y, Mullen GM, et al. Heart transplantation as a treatment option for end-stage heart disease in patients older than 65 years of age. J Heart Lung Transplant. 1993;12:573-9.

6. Bull DA, Karwande SV, Hawkins JA, Neumayer LA, Taylor DO, Jones $\mathrm{KW}$, et al. Long-term results of cardiac transplantation in patients older than sixty years. J Thorac Cardiovasc Surg. 1996;111: 423-8.

7. Hosenpud JD, Bennett LE, Keck BM, Boucek MM, Novick RJ. The registry of the International Society for Heart and Lung Transplantation: seventeenth official report. J Heart Lung Transplant. 2000;19: 909-31.

8. Stinson EB, Dong E Jr, Schroeder J, Harrison DC, Shumway NE. Initial clinical experience with cardiac transplantation. Am J Cardiol. 1968;22:791-803. 
9. Robbins RC, Barlow CW, Oyer PE, Hunt SA, Miller JL, Reitz BA, et al. Thirty years of cardiac transplantation at Stanford University. J Thorac Cardiovasc Surg. 1999;117:939-51.

10. Rose EA, Gelinjns AC, Moskowitz AJ, Heitjan DF, Stevenson LW, Dembitski W, et al. Long-term use of a left ventricular assist device for end-stage heart failure. $N$ Engl J Med. 2001;345:1435-43.

11. Laks H, Marelli D. The alternate recipient list for heart transplantation: a model for expansion of the donor pool. Adv Card Surg. 1999;11: 233-44.

12. Lower RR, Shumway NE. Studies on orthotopic transplantation of the canine heart. Surg Forum. 1960;11:18-20.

13. Billingham ME, Cary NR, Hammond ME, Kemnitz J, Marboe C, McAllister HA, et al. A working formulation for the standardization of nomenclature in the diagnosis of heart and lung rejection: Heart Rejection Study Group. J Heart Transplant. 1990;9:587-92.

14. Blanche C, Blanche DA, Kearney B, Sandhu M, Czer LSC, Kamlot A, et al. Heart transplantation in patients seventy years of age and older: a comparative analysis of outcome. J Thorac Cardiovasc Surg. 2001; 121:532-41.

15. Robbins RC. Ethical implications of heart transplantation in elderly patients. J Thorac Cardiovasc Surg. 2001;121:434-5.

16. Conraads VM, Denollet J, Vorlat A, Moulijn AC, Vrints CJ. Screening for solid organ malignancies prior to heart transplantation. Transplantation. 2001;71:1481-3.

17. Caforio ALP, Gambino A, Piaserico S, Tona F, Belloni Fortina A, Feltrin G, et al. De novo noncutaneous malignancies in heart transplantation: a single-center 15 -year experience and risk factor analysis. Transplant Proc. 2001;33:3658-9.

18. Borkon AM, Muehlebach GF, Jones PG, Bresnahan DR, Genton RE, Gorton ME, et al. Analysis of the effect of age on survival after heart transplantation. J Heart Lung Transplant. 1999;18:668-74.

19. Baron O, Trochu JN, Treilhaud M, al Habash O, Remadi JP, Petit T, et al. Cardiac transplantation in patients over 60 years of age. Transplant Proc. 1999;31:75-8.

20. Crespo-Leiro MG, Paniagua MJ, Rodriguez JA, Hermida LF, Fojon S, Vasquez N, et al. Morbidity and mortality among patients older and younger than 65 years. Transplant Proc. 1999;31:2537-8.
Appendix 1. Pretransplantation and perioperative variables evaluated as potential independent risk factors for early and late deaths in the multivariable analysis

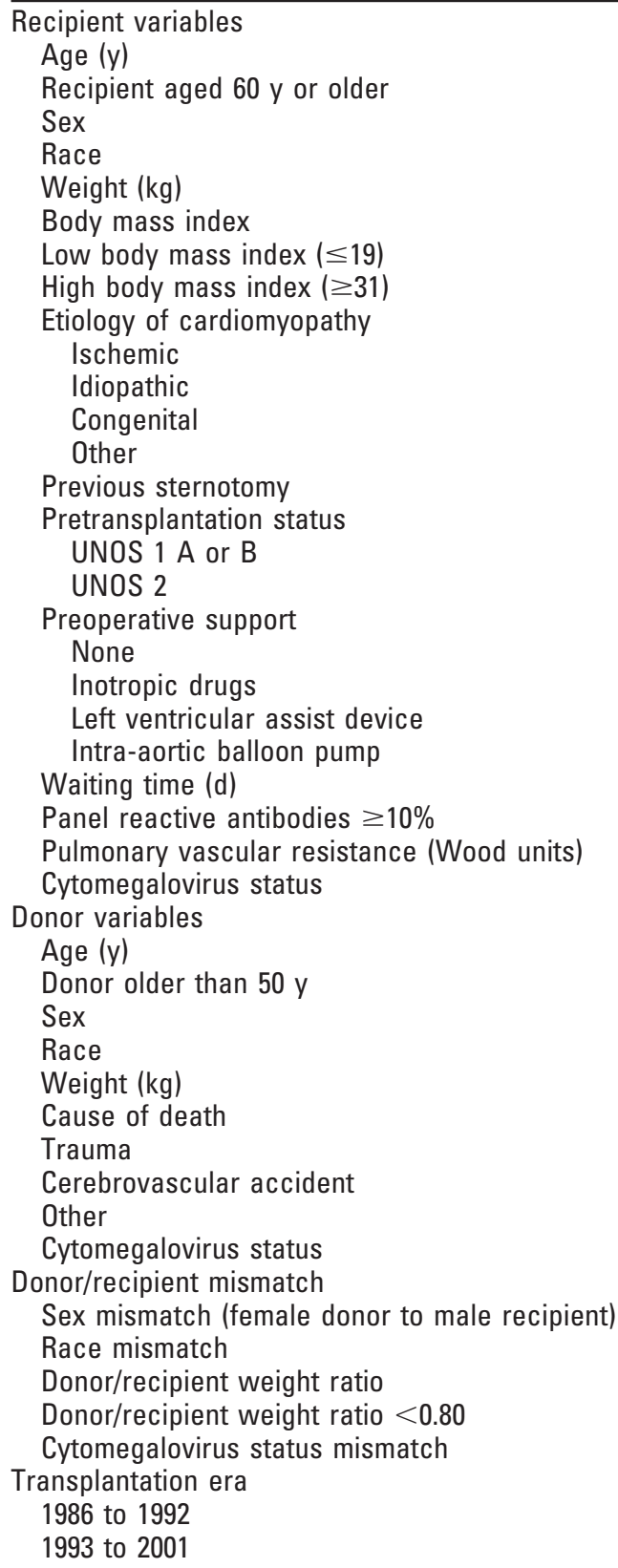

